\title{
Sensorimotor changes and functional performance in patients with knee osteoarthritis
}

\author{
Michael V Hurley, David L Scott, Joanne Rees, Di J Newham
}

\begin{abstract}
Objective-Muscles are essential components of our sensorimotor system that help maintain balance and perform a smooth gait, but it is unclear whether arthritic damage adversely affects muscle sensorimotor function. Quadriceps sensorimotor function in patients with knee osteoarthritis (OA) was investigated, and whether these changes were associated with impairment of functional performance.
\end{abstract}

Methods-Quadriceps strength, voluntary activation, and proprioceptive acuity (joint position sense acuity) were assessed in 103 patients with knee $O A$ and compared with 25 healthy control subjects. In addition, their postural stability, objective functional performance (the aggregate time for four activities of daily living), and disabilities (Lequesne index) were also investigated.

Results-Compared with the control subjects, the patients with knee OA had weaker quadriceps (differences between group mean $100 \mathrm{~N}$, CI $136,63 \mathrm{~N})$, poorer voluntary activation $(20 \%$ CI $13,25 \%)$ that was associated with quadriceps weakness, and impaired acuity of knee joint position sense $\left(1.28^{\circ}, \mathrm{CI} 0.84,1.73^{\circ}\right)$. As a group the patients were more unstable $(p=0.0017)$, disabled $(10, \mathrm{CI} 7,11)$, and had poorer functional performance (19.6 seconds, CI 14.3, 24.9 seconds). The most important predictors of disability were objective functional performance and quadriceps strength.

Conclusions-In patients with knee OA, articular damage may reduce quadriceps motoneurone excitability, which decreases voluntary quadriceps activation thus contributing to quadriceps weakness, and diminishes proprioceptive acuity. The arthrogenic impairment in quadriceps sensorimotor function and decreased postural stability was associated with reduced functional performance of the patients.

(Ann Rheum Dis 1997;56:641-648)
Osteoarthritis (OA) causes much musculoskeletal pain and disability. ${ }^{12}$ The knee joint is commonly involved and its treatment requires expenditure of large amounts of health resources. ${ }^{23}$ Despite its prevalence and healthcare costs, conservative management of knee $\mathrm{OA}$ is often inadequate and many patients suffer prolonged pain and disability, with considerable socioeconomic consequences. ${ }^{13}$

Synovial joints are complex structures that facilitate movement, dexterity, and function. Movement is effected by the volitional contraction of skeletal muscles that cross the joint and limited by ligaments. The pathological, biochemical, and structural changes in articular cartilage and subchrondral bone in knee OA have been extensively investigated. However, the pathological changes that occur in the muscles acting across the knee joint have not been investigated to the same extent, even though quadriceps weakness and fatigue are frequent and early complaints of patients with knee OA. ${ }^{2-6}$

As well as generating force and producing movement, skeletal muscle also functions as an organ of proprioception. Proprioceptive acuity requires the integrity of all the sensory systems that contribute to its appreciation-that is, muscle spindles, Golgi tendon organs, articular and cutaneous proprioceptors, the visual field, and vestibular apparatus. ${ }^{78}$ Of these muscle spindles, which furnish sensory information regarding muscle length (that is, joint position sense) and velocity of muscle stretch, are considered to be of prime importance. ${ }^{9-11}$ Consequently pathology that adversely affects muscle function may impair force generation and proprioceptive acuity of muscle.

The integrity and control of sensorimotor systems (that is, proprioceptive acuity and muscle contraction) are essential for the maintenance of balance ${ }^{78}$ and production of a smooth, stable gait. If knee OA impairs quadriceps function this may impair the patient's balance and gait, reducing their mobility and function.

To investigate the changes and consequences of knee OA on muscle sensorimotor function we assessed quadriceps strength, voluntary activation, and proprioceptive acuity in patients with $\mathrm{OA}$ knees, and investigated whether these changes were associated with 
Table 1 Anthropometric, muscle function, and functional performance data of the patients and control subjects. The data are presented as mean (95\% confidence intervals) unless otherwise stated

\begin{tabular}{|c|c|c|c|c|c|}
\hline & Patients (n) & Patients & Controls (n) & Control subjects & $\begin{array}{l}\text { Difference between group } \\
\text { means }(95 \% \mathrm{CI})\end{array}$ \\
\hline \multicolumn{6}{|l|}{ Anthropometric data } \\
\hline Age $(y)$ & 103 & $60.73(58.7,62.73)$ & 25 & $65.6(61.66,69.54)$ & $4.9(-9.5,0.5)$ \\
\hline Body mass $(\mathrm{kg})$ & 103 & $76.95(74.09,79.81)$ & 25 & $73.96(67.49,80.43)$ & $2.99(-4.0,10.0)$ \\
\hline Height $(\mathrm{m})$ & 103 & $1.65(1.62,1.66)$ & 25 & $1.64(1.61,1.68)$ & $0.01(-0.05,0.03)$ \\
\hline \multicolumn{6}{|l|}{ Muscle function data } \\
\hline Quadriceps MVC (N) & 103 & $235(209,261)$ & 25 & $335(308,361) \dagger$ & $100(136,63)$ \\
\hline Median quadriceps activation (\%) & 103 & $72.5(66.95,79.35)$ & 25 & $93.0(92.00,95.00) \dagger$ & $20.5(13,25)$ \\
\hline JPS mean error (degree) & 69 & $3.57(3.22,3.92)$ & 25 & $2.29(2.00,2.57) \dagger$ & $1.28(0.84,1.73)$ \\
\hline \multicolumn{6}{|l|}{ Postural stability } \\
\hline Bipedal stance, eyes open (degree) & 80 & $0.120^{\star}(0.104,0.136)$ & 25 & $0.103^{\star}(0.086,0.119)$ & $0.017(-0.005,0.040)$ \\
\hline Bipedal stance, eyes closed (degree) & 76 & $0.237(0.214,0.260)$ & 25 & $0.211(0.178,0.278)$ & $0.026(-0.012,0.065)$ \\
\hline Monopedal stance, eyes open (degree) & 65 & $0.256(0.222,0.288)$ & 25 & $0.233(0.187,0.278)$ & $0.023(-0.033,0.078)$ \\
\hline \multicolumn{6}{|l|}{ Functional performance data } \\
\hline $\operatorname{AFPT}(\mathrm{s})$ & 103 & $55.24(50.70,59.77)$ & 25 & $35.62(32.7,38.6) \dagger$ & $19.62(14.3,24.9)$ \\
\hline Median Lesquesne index & 103 & $11(10.42,12.08)$ & 25 & $1.00(0,3) \dagger$ & $10(7,11)$ \\
\hline
\end{tabular}

JPS $=$ joint position sense AFPT $=$ aggregate functional performance time .

$\star$ Significantly more stable $(\mathrm{p}<0.001)$ than bipedal stance with eyes closed and monopedal stance with eyes open.

† Significant difference $(\mathrm{p}<0.0001)$ between patients and control subjects.

impairment of functional performance and disability. These results were compared with data from a control group of healthy subjects with no knee abnormality.

\section{Methods}

PATIENTS

Quadriceps function, postural stability, and functional performance were assessed in 103 patients (38 men) of mean age 61 years (range 28-83). Diagnosis of knee OA was made by a senior rheumatologist from the clinical history and physical examination of the patient. ${ }^{12-14}$ All the patients had knee pain and fulfilled the ACR criteria for knee OA. ${ }^{15}$ The patient's age, sex, general medical history, history of knee complaint, knee pain (including duration, diurnal pattern, exacerbating and alleviating factors), effusion, mechanical dysfunction and joint instability, deformities, presence and duration of knee stiffness, tenderness (medial, lateral, and patellofemoral), crepitus (tibiofemoral and patellofemoral), and bony swelling were recorded. ${ }^{12-14}$ The presence of bony changes was confirmed by anteroposterior and lateral weightbearing radiograms. However, it was not the aim of this study to examine the association between severity of clinical presentation and severity of radiological changes or compartmental involvement of knee OA, therefore the radiographs were not graded and no analysis of these associations were performed.

Forty six patients were not taking medication, 33 had been advised to take simple analgesia as required (for example, paracetamol or codeine only), and 24 were treated with non-steroidal anti-inflammatory drugs (NSAIDs, for example, diclofenac).

Sixty four patients had bilateral OA knee, data from the knee these patients considered was worst affected were used in the data analysis.

Patients who reported previous episodes of mild pain in other joints were included (for example, hands $(n=22)$, hips $(n=18)$, ankles $(n=9)$, and spine $(n=7))$. Patients were excluded if they reported significant pain during the assessment procedures, or whose clinical examination or history revealed low back pain or symptomatic OA in ipsilateral or contralat- eral weightbearing joints (other than the contralateral knee) that might have influenced the results. Other exclusion criteria were unstable, co-existing medical conditions (for example, cardiovascular or neurological conditions; vestibular disturbance; diabetes).

As a comparative group, 25 healthy control subjects (seven men) were also assessed (mean age 65 years, range 50-82). They were recruited from local clubs and groups if they were in good general health and living independently in the community. None of the control subjects had a history of recurrent knee pain, and were excluded if they had a recent (within previous 12 months) single episode of knee pain or serious knee injury. Data were included from four control subjects with minor radiological changes but who were asymptomatic. The possibility that 'volunteer bias' may have affected the results cannot be discounted.

Table 1 gives anthropometric details of the patients and control subjects.

MEASUREMENT OF ISOMETRIC QUADRICEPS FORCE AND ACTIVATION

Quadriceps force

The patients were seated on a specially constructed chair with their hips and knees flexed to $90^{\circ}$ and a restraining strap across their pelvis to minimise unwanted hip, pelvic girdle, and lower trunk movement. A non-extensible strap was placed around their lower leg just above the malleoli, the other end was attached to a strain gauge that was clamped onto the frame of the chair. The patients were instructed to straighten their knee, pushing as hard as they could against the ankle strap. Because the nonextensible strap prevented joint movement an isometric maximum voluntary contraction (MVC) was produced. The signal from the strain gauge was amplified, processed by an A-D converter (CED, Cambridge, UK), displayed on a personal computer using 'Chart' data handling software (CED, Cambridge, UK), and collected for off line analysis using 'Signal Averager' software (CED, Cambridge, $\mathrm{UK})$.

Estimation of quadriceps voluntary activation The degree of quadriceps voluntary activation was estimated by superimposing percutaneous 
electrical stimulation upon isometric MVCs. ${ }^{16}$ With the patients positioned as described above, two malleable electrodes (10 $\times 15 \mathrm{~cm}$ ) were placed in a dampened sponge sleeve to improve electrical conductivity, which were then bandaged onto the proximal and distal aspects of their anterior thigh. A train of about 10 electrical stimuli (frequency $1 \mathrm{~Hz}$, pulse width $50 \mu \mathrm{s}, 400$ volts, and $375 \mathrm{~mA}$ ) were delivered through these electrodes. The amplitudes of five electrical stimuli delivered to the resting muscle were recorded (mean amplitude approximately $20-25 \%$ of the MVC), then the patient was instructed to perform a four/five second MVC as described above, while the stimuli train continued.

If the muscle is fully activated then electrical stimulation does not generate additional force. However, if the muscle is not fully activated additional force is generated by each electrical impulse; the smaller the force of the submaximal contraction, the greater the amplitude of the superimposed twitch. The extent of incomplete activation can be estimated by comparing the relative amplitudes of the resting and superimposed twitches. ${ }^{18}$ The coefficient of variation of this technique is approximately $8 \% .^{18} 19$

To minimise the patients apprehension, and facilitate full activation and the generation of MVCs each patient received a full explanation and was familiarised with the test procedures. In addition, during the contractions they were given vigorous verbal encouragement and aided by real time visual feedback of the force trace displayed on the computer monitor. Between each MVC a one minute recovery period was allowed to minimise fatigue. Three isometric quadriceps MVC with superimposed electrical stimulation were recorded, but only the largest MVC used in the data analysis.

During each quadriceps MVC and assessment of voluntary activation the patients were questioned about pain. If pain was reported they were asked to verbally rate the pain on a scale of $0-10(0=$ no pain, $10=$ the worst pain they ever experienced in their knee). Although all the patients reported pain as a significant clinical feature of their knee condition, usually during weightbearing activities, the vast majority of patients $(n=81$, about $80 \%)$ tolerated the non-weightbearing assessments of quadriceps strength and activation extremely well, reporting no or very little pain. Patients who reported pain $(n=30)$ were asked if they considered the pain was impeding muscle contraction; eight of these patients considered the pain was impeding their ability to produce an MVC, and as this was an exclusion criterion they were deemed unsuitable for participation in the trial.

\section{JOINT POSITION SENSE}

In a quiet environment the patients were blindfolded and seated on a high chair with their lower legs hanging relaxed and unsupported over the edge of the seat. An electrogoniometer (Penny and Giles, Gwent, UK) was attached to lateral aspect of the patients knee using double sided sticky tape. The proximal electrogoniometer block was placed just above the lateral femoral epicondyle in line with the greater trocanter, and the distal block just below the head of the fibula in line with the lateral malleolus. In this 'resting position' the electrogoniometer display was set to zero. The patients were instructed to slowly straighten their knee and told to stop at a random angle. This 'test angle' indicated on the display was noted. For approximately five seconds they were asked to maintain and mentally visualise the position of their knee. They were then told to relax, allowing their leg to hang freely in the resting position, and after three seconds the patients were asked to reproduce the test angle. The 'reproduced angle' on the display was recorded. The procedure was performed for 10 different test angles between $90^{\circ}$ flexion and full knee extension. The mean error between the 10 test and reproduced angles was calculated. A previous report has shown this technique to be reliable and reproducible. ${ }^{20}$

POSTURAL STABILITY

Postural stability, or body sway, was assessed by estimating the displacement of the patient's centre of gravity (CoG) from the vertical. A custom designed 'swaymeter' consisting of a force plate with strain gauges and computer software was built. ${ }^{21}$ The patients stood in the centre of a force plate with their feet placed slightly apart, their arms by their sides, and asked to remain as still as possible for 10 seconds. For the first three seconds the mean position of the patient's CoG was assessed, then for seven seconds the swaymeter traced the displacement of the patient's CoG from this mean position. The software program estimated body sway by assuming the body behaved like an inverted cone with sway occurring at the ankles; the mean displaced CoG distance was the radius of the base of the inverted cone, and the height of the cone was the height of the patient's CoG (calculated from the patient's height), using these measures the mean angle of displacement of the CoG from the vertical can be calculated..$^{21}$ The swaymeter produces a reliable estimation of postural stability with a coefficient of variance of $4 \% .^{20}{ }^{21}$

Postural stability was assessed in three stance conditions, (a) bipedal stance with eyes open, (b) bipedal stance with eyes closed, and (c) monopedal stance on their affected leg with eyes open. During these stance assessments if patients tried to prevent over-balancing by grabbing a safety bar or placing their nonstance leg on the swaymeter during monopedal stance, the assessment was deemed unsuccessful and was repeated. Three attempts were permitted, if all three were unsuccessful the patient was deemed unable to perform that stance condition and the data excluded from the analysis of that stance condition. The number of patients who successfully completed each stance condition is shown in table 1 .

\section{FUNCTIONAL PERFORMANCE}

Fifty feet timed walk ${ }^{22}$

The patients were asked to walk as fast as they could along a level, unobstructed corridor on 


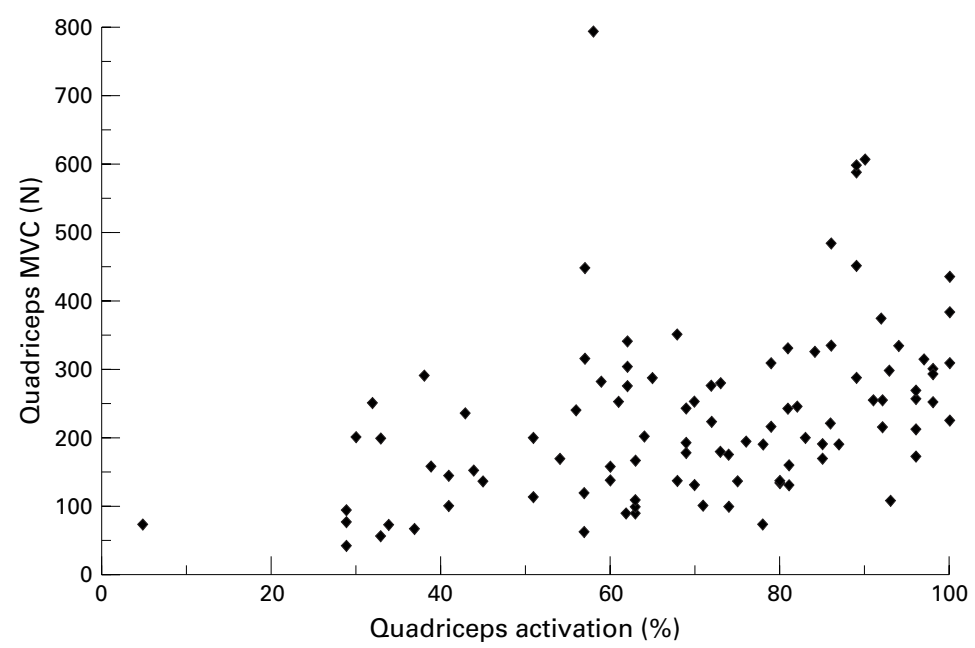

Figure 1 Scattergram of quadriceps strength and voluntary activation of patients with knee $O A$. Quadriceps strength was directly related to voluntary activation of the muscle $\left(r_{s}=0.486, p<0.001\right)$. MVC, maximum voluntary contraction. $N$, Newtons.

the command 'Go'. A hand held stopwatch was started as the subject passed a pre-determined start mark, and stopped as they passed a second mark 50 feet from the start mark.

The 'Get up and Go' test ${ }^{23}$

The patients were seated on a chair with arm rests and instructed on the command 'Go' to stand up and walk along a level, unobstructed corridor as fast as they could. The stopwatch was started on the command, and stopped when the subject passed a pre-determined mark 50 feet from the chair.

\section{Stairs ascent}

The patients stood at the bottom of a straight flight of stairs, consisting of $11,12 \mathrm{~cm}$ high steps, and asked to ascend the stairs on the command 'Go'. The stopwatch was started on the command and stopped when the subject placed their second foot on the top step of the flight of stairs.

Stairs descent

The patients stood at the top of the flight of stairs. When instructed to descend the stairs the stopwatch was started on the command and stopped when the subject placed their second foot on the floor at the bottom of the stairs.

AGGREGATE FUNCTIONAL PERFORMANCE TIME

Any single test of functional performance imparts little information about the patients overall functional ability - that is, walking on a smooth floor gives little information about the dynamic balance required to stand up and walk across a room or ascend stairs. By aggregating the time of the four activities a better objective assessment of the patient's overall functional capabilities can be obtained, this was called the aggregate functional performance time (AFPT).

LEQUESNE INDEX

The Lequesne index for knee $\mathrm{OA}$ is a pathology specific subjective assessment of disability. ${ }^{24}$ Patients were asked to rate their pain and abil- ity to perform various ADL, scoring between 0 and 24 points. Lower scores indicate better subjective functional abilities. To investigate the relation of quadriceps strength and objective functional performance with disability, the Lequesne index was used to arbitrarily categorise the severity of the patient's disability as mild/moderate knee (Lequesne index <7), severe/very severe OA (Lequesne index $>7$ but $<14$ ), and extremely severe (Lequesne index $>14) .{ }^{24}$

ETHICAL APPROVAL

Ethical approval was obtained from the King's College Hospital Ethics Committee. Each subject was given written and verbal information about the study and signed a consent form.

\section{DATA ANALYSIS}

Level of significance was set at $\mathrm{p}<0.01$. Statistical testing was performed using 'Minitab' version 10.2. All tests are two tailed.

For normally distributed data-that is, quadriceps MVC, JPS, postural stability, and AFPT - the data are presented as the mean with $95 \%$ confidence intervals (CI). Differences between these parameters of patients with knee OA and the healthy subjects, and between patient sub-groups, were assessed using unpaired $t$ tests. The degree of association between these parameters was estimated using the Pearson correlation coefficient, $r$.

As the quadriceps activation was right skewed and the Lequesne index was ordinal data, these data are presented as the median with $95 \%$ CI. Differences between these parameters in the patients and healthy subjects, and between patient sub-groups were assessed using the Mann-Whitney test. The degree of association with these parameters was estimated using a non-parametric correlation-that is, Spearman's rank correlation coefficient, $r_{s}$.

Fisher's exact test was used to determine whether patients with knee OA had greater postural sway than the healthy subjects.

To investigate which variables explain most of the patient's disability a multiple regression model was constructed with the Lequesne index as the dependent variable and age, body mass, quadriceps strength and activation, JPS, AFPT and bipedal stance with eyes open as the explanatory variables, and a forward stepwise regression analysis performed.

\section{Results}

\section{QUADRICEPS MVC AND ACTIVATION}

The patients with knee OA had weaker quadriceps than the control subjects, and could activate less of their quadriceps during an MVC (table 1). As the patient's ability to activate their quadriceps decreased their quadriceps MVC also decreased $\left(r_{s}=0.486, \mathrm{p}<0.001\right.$; fig 1$)$.

\section{JOINT POSITION SENSE}

To accurately assess knee JPS the patients had to actively extend their knee, maintain the test position for five seconds, and reproduce that angle for five seconds, so that a steady joint angle could be recorded. This was then repeated nine times at different angles. Unfortunately 34 


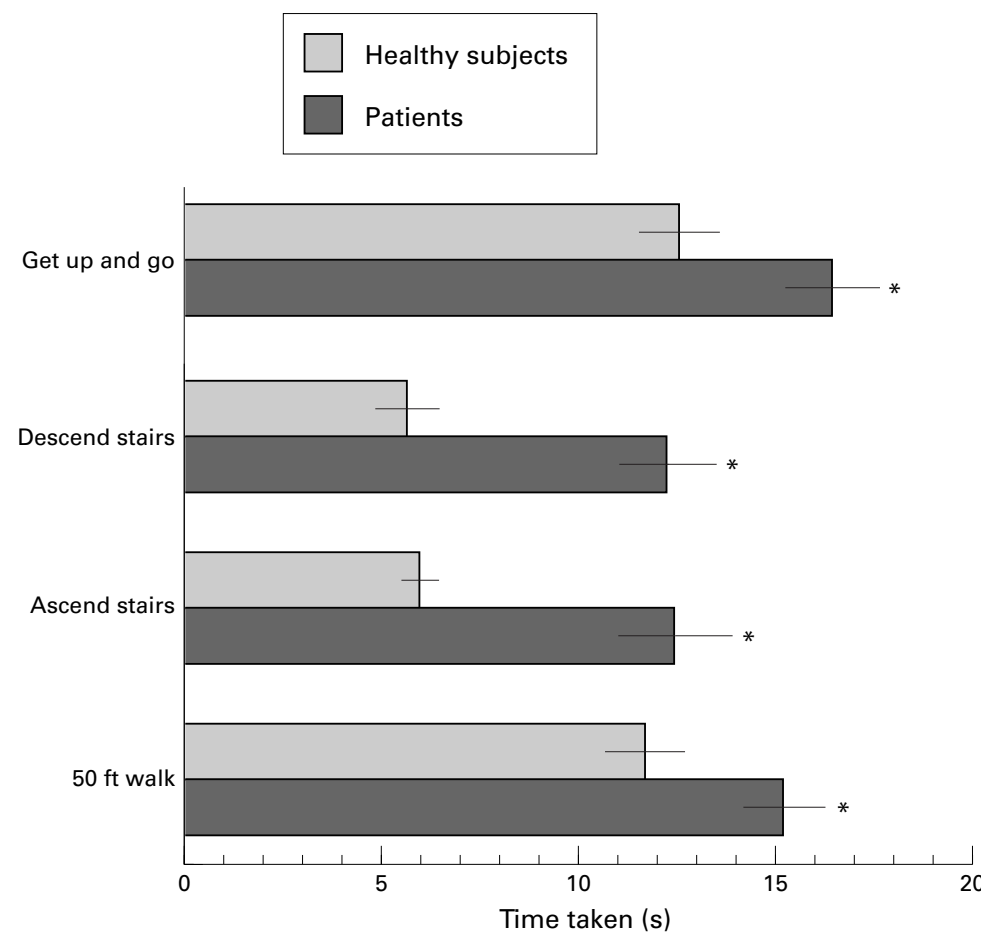

Figure 2 Time taken for the patients with knee $O A$ and healthy subjects to perform the four common activities of daily living used to objectively assess functional performance. (Mean with $95 \%$ CI error bars). * Significantly slower $(p<0.0001)$ than the healthy subjects.

patients found maintenance of steady knee position too difficult because of quadriceps weakness or poor control, therefore a reliable assessment of JPS was obtained for 69 patients only. Their mean error of JPS was greater-that is, they were less accurate-than the control subjects (table 1).

\section{POSTURAL STABILITY}

All the control subjects could maintain their balance for seven seconds during the assessment of postural stability. However, many patients were too unsteady to maintain stance for seven seconds, the numbers of patients who were able to perform each stance condition are shown in table 1 . As a group patients with knee OA were less stable than the control subjects, this is shown by the numbers of patients unable to maintain bipedal stance with their eyes open for seven seconds $(p=0.0017$, Fisher's exact test).

For any of stance condition there was no difference between the postural stability of the patients who could maintain that stance condition and the control subjects (table 1). The postural stability of these patients and the control subjects decreased when their visual field was removed or their base of support reduced (table 1).

There was no association between quadriceps strength or JPS and postural stability.

FUNCTIONAL PERFORMANCE AND DISABILITY Objective assessment of functional performance The patients were slower than the control subjects in all the individual tests of ADL (fig 2), and their aggregate functional performance time (AFPT) was greater (table 1). In the patient group there was an inverse relation between quadriceps MVC and their AFPT $(r=-0.402, \quad p<0.001)$ - that is, quadriceps weakness was associated with a deterioration in objective assessment of functional performance. The AFPT of patients with unilateral knee OA was better those with bilateral knee OA (table 2).

\section{Disability}

The median Lequesne index of the patients was greater than the control subjects (table 1) - that is, they were more disabled - and was inversely related to their quadriceps $\operatorname{MVC}\left(r_{s}\right.$ $=-0.385, \mathrm{p}<0.001 ;$ fig $3 \mathrm{~A}$ ). When the Lequesne index was used to arbitrarily define the severity of the disability, ${ }^{24}$ the mean quadriceps strength (fig 3A) and AFPT (fig 3B) deteriorated as the severity of disability increased. Patients with bilateral knee OA were more disabled than patients with unilateral involvement (table 2).

There was a good correlation between the patient's Lequesne index and objective assessment of functional performance, $\left(r_{s}=0.665\right.$, $\mathrm{p}<0.001$; fig 3B), therefore objective assessment of their functional performance reflects the patient's subjective assessment of their functional ability.

Forward stepwise multiple regression indicated that AFPT and quadriceps strength accounted for $45 \%$ of the variance in the Lequesne index, but addition of other variables (that is, age, body mass, quadriceps activation, JPS, or bipedal stance with eyes open) to the model did not significantly influence the Lequesne index.

COMPARISON OF PATIENTS WHO COULD AND COULD NOT MAINTAIN BIPEDAL STANCE WITH EYES OPEN

The quadriceps MVC, activation and JPS of the patients who could maintain bipedal stance with eyes open for seven secondss were similar to the patients who could not maintain this stance condition. However, the AFPT and Lequesne index were worse in the patients who

Table 2 Comparison of the objective functional performance, the ASPT, and Lequesne index for disability of knee OA between male and female patients, patients with unilateral and bilateral knee $O A$, and patients who could not maintain bipedal stance with their eyes open for seven seconds

\begin{tabular}{|c|c|c|c|c|c|c|c|c|c|}
\hline & Men & Women & $\begin{array}{l}\text { Difference } \\
\text { between group } \\
\text { means }\end{array}$ & $\begin{array}{l}\text { Unilateral } \\
\text { knee } O A\end{array}$ & $\begin{array}{l}\text { Bilateral knee } \\
O A\end{array}$ & $\begin{array}{l}\text { Difference } \\
\text { between group } \\
\text { means }\end{array}$ & $\begin{array}{l}\text { Able to perform } \\
\text { bipedal stance } \\
\text { with eyes open }\end{array}$ & $\begin{array}{l}\text { Unable to } \\
\text { perform } \\
\text { bipedal stance } \\
\text { with eyes open }\end{array}$ & $\begin{array}{l}\text { Difference } \\
\text { between group } \\
\text { means }\end{array}$ \\
\hline Mean AFPT/s (CI) & $\begin{array}{l}48.97(42.3, \\
55.7)\end{array}$ & $\begin{array}{l}58.91(52.9, \\
64.9)\end{array}$ & $\begin{array}{l}9.4(-18.8, \\
-1.1)\end{array}$ & $\begin{array}{l}48.0(42.9, \\
53.1)\end{array}$ & $\begin{array}{l}59.77(53.4, \\
66.2)\end{array}$ & $\begin{array}{l}11.77^{\star} \\
(-19.9,-3.7)\end{array}$ & $\begin{array}{l}51.96(47.26, \\
56.66)\end{array}$ & $\begin{array}{l}66.85(55.5, \\
75.5)\end{array}$ & $\begin{array}{l}12.89^{\star} \\
(-27.3,-2.5)\end{array}$ \\
\hline $\begin{array}{l}\text { Median Lequesne } \\
\text { index (CI) }\end{array}$ & $\begin{array}{l}9.5(7.5 \\
11.25)\end{array}$ & $\begin{array}{l}12(10.5 \\
12.75)\end{array}$ & $\begin{array}{l}2.5(-4.5 \\
-0.0)\end{array}$ & $9(7,10)$ & $\begin{array}{l}12.5(11.25 \\
13.5)\end{array}$ & $3.5^{\star}(-6,-2)$ & $\begin{array}{l}10.75(8.75 \\
11.25)\end{array}$ & $\begin{array}{l}14(11.5, \\
16.0)\end{array}$ & $\begin{array}{l}3.25^{\star}(-6.0 \\
-1.5)\end{array}$ \\
\hline
\end{tabular}

^ Significant difference between the groups $(\mathrm{p}<0.01)$. 
could not maintain bipedal stance with eyes open (table 2), and as their postural sway increased there was a proportional increase in AFPT $(r=0.311, \mathrm{p}<0.007)$ and Lequesne index $\left(r_{s}=0.318, \mathrm{p}<0.007\right)$ - that is, poor balance was associated with reduced objective functional performance and disability.

INFLUENCE OF NSAID MEDICATION

To see if NSAID medication affected the assessment parameters, the data of the patients taking NSAIDs were analysed and compared with the patients who were not taking NSAIDs. There were no differences between any of the test parameters (that is, quadriceps strength and activation, JPS, AFPT, Lequesne index or postural stability tests) of these two patient groups.

\section{Discussion}

This study found that compared with healthy subjects, patients with knee OA have quadriceps weakness, decreased proprioceptive acuity, and poor postural stability, which were associated with a decrease in subjective and objective functional performance.

As healthy people age there is a decrease in quadriceps strength, ${ }^{25-30}$ but this is not caused
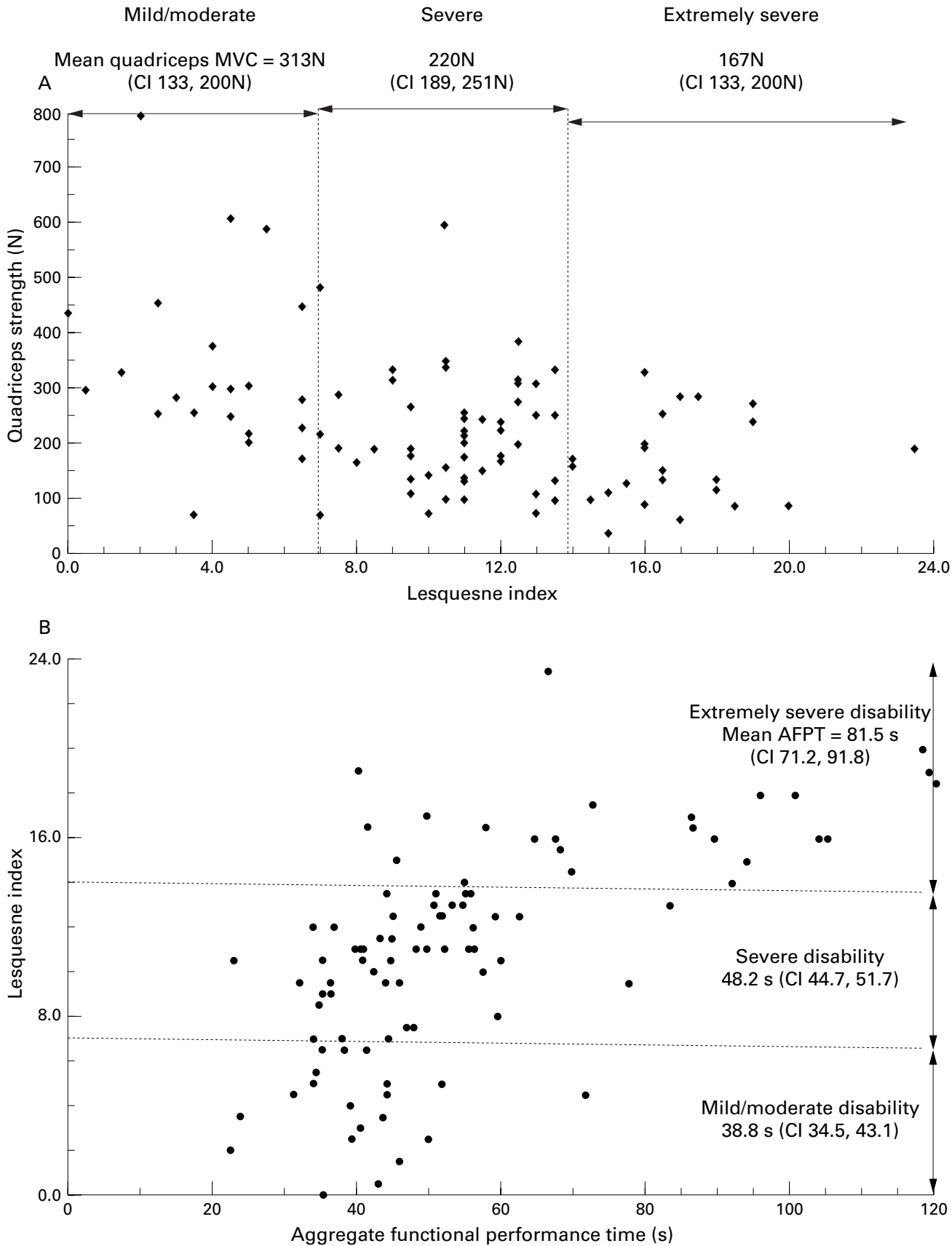

Figure 3 (A) Lequesne index and quadriceps strength of patients with knee $O A$. As quadriceps strength decreased the patient's disability increased $(r=-0.385, p<0.001)$. Mean quadriceps strength decreased in each arbitrarily defined category of disability $(p<0.001)$. (B) Lequesne index and the aggregate functional performance time of the patients with knee $O A$. As the Lequesne index for disability increased the aggregate time of the tests increased $\left(r_{s}=0.665, p<0.001\right)$. The mean AFPT increased at each arbitrarily defined level of disability $(p<0.001)$. 
by an age related reduction in voluntarily activation $^{28} 3031$ and patients with knee OA have a greater quadriceps weakness. ${ }^{24-6}$ Some of this disproportionate weakness may result from muscle atrophy as patient's normal activities are restricted because of pain or decreased confidence, but this study shows that incomplete activation of their quadriceps during a volitional contraction will contribute to the weakness.

Joint pain $^{32}$ and effusions $\mathrm{s}^{33-36}$ are known to cause an arthrogenic reduction in activation. However, in this study during the assessments of quadriceps voluntary activation and strength the patients reported no pain or very mild pain, and none of them had clinical effusions. In these patients articular damage may stimulate articular mechanoreceptors evoking abnormal sensory information, which decreases voluntary activation. ${ }^{55}{ }^{37}$ Afferent fibres from articular mechanoreceptors project (via interneurones) onto $\alpha$-motoneurones in the spinal cord, and these $\alpha$-motoneurones activate extra-fusal muscle fibres. ${ }^{9}{ }^{38-40}$ If articular damage evokes abnormal afferent information, which in turn decreases the excitability of $\alpha$-motoneurones, this would reduce voluntary activation of the quadriceps. ${ }^{38-40}$

Articular mechanoreceptor's afferent fibres also project onto $\gamma$-motoneurones in the spinal cord. ${ }^{41-44} \gamma$-Motoneurones activate the intrafusal muscle fibres that make up muscle spindles. Thus $\gamma$-motoneurone excitability governs muscle spindle sensitivity. ${ }^{910}$ If arthritic damage to articular mechanoreceptors evokes sensory input that reduces $\gamma$-motoneurone excitability, this would decrease muscle spindle sensitivity and consequently decrease proprioceptive acuity. ${ }^{43} 4546$

Therefore damage of articular mechanoreceptors may impair both motor control (that is, voluntary muscle activation) and sensory appreciation (that is, JPS) in patients with knee OA.

The integrity of our sensorimotor systems is essential to effect a smooth, stable gait. Proprioceptive acuity ensures accurate timing and placement of the lower limb at heel strike, ${ }^{39} 4344$ and eccentric quadriceps activity after heel strike minimises the affect of joint loading. It has been suggested that poorly controlled gait may be a factor predisposing knee OA. ${ }^{47}$ In vivo animal studies show that rapidly applied - that is, impulsive-loading of synovial joints causes cartilage destruction. ${ }^{48}$ In humans, mild knee pain has been associated with a habitual gait that involves high impulsive loading at heel strike, ${ }^{47}$ unfortunately it is difficult to ascertain whether pain causes increased impact loading or greater loading precedes pain. The quadriceps may have an important role in controlling impulsive forces at the knee at heel strike, as quadriceps paralysis of subjects who do not have knee pain increases the impulsive loading. ${ }^{49}$ Changed sensory input from articular mechanoreceptors may decrease quadriceps strength and proprioceptive acuity, impairing neuromuscular protective mechanisms that attenuate potentially harmful impact forces after heel strike, thereby accelerat- ing articular damage. ${ }^{50}{ }^{51}$ Therefore as a result of joint damage or because of normal aging processes, impaired quadriceps sensorimotor function may be an important factor in the pathogenesis of OA damage.

In common with other studies of patients with arthritis we found that patients with OA knees are less stable than healthy subjects. ${ }^{5253}$ Although the postural stability of our patients that could maintain the stance conditions was similar to the healthy subjects, one in five patients were too unsteady to maintain bipedal stance with their eyes open for a relatively brief period. However, neither quadriceps weakness $^{5455}$ nor decreased acuity of knee JPS were associated with decreased postural stability, suggesting other factors have important influences on the patient's postural stability. ${ }^{56}$ These factors include proprioceptive input from other articular, muscle, and cutaneous mechanoreceptors in the lower limb, the visual field, and vestibular apparatus, and importantly the patient's confidence and anxiety of falling.

Disability and objective functional performance were much worse for the patients with OA knees and were most strongly influenced by quadriceps weakness, emphasising the importance of quadriceps weakness as a determinant of disability in patients with knee OA. ${ }^{2}{ }^{4}$ As the quadriceps are important for functional knee stability, ${ }^{44}$ impairment of quadriceps sensorimotor function will make the patient feel weak, unstable, and decrease their confidence. As a consequence this will impair their mobility and performance of ADL, leading to decreased personal independence.

As stated, aggregation of the time taken to walk a short distance, stand up and walk, ascend and descend a flight of stairs was performed to provide a better objective assessment of the patient's overall functional capabilities, the AFPT. It should be emphasised that although there was a good correlation between the Lequesne index and the AFPT, further validation of the AFPT is required and it needs to be ensured that no single activity has an undue influence on the aggregate time.

In conclusion, patients with knee OA have quadriceps sensorimotor deficits, some of which were associated with decreased postural stability and a deterioration in functional performance and disability. Arthritic damage to articular mechanoreceptors may evoke abnormal afferent discharge that decreases $\alpha-$ and $\gamma$-motoneurones excitability, impairing motor control, and proprioceptive acuity. These sensorimotor deficits reduce the patient's stability, undermine their confidence, and lead to a deterioration in function. Moreover, the impairment of neuromuscular protective mechanisms may be involved in the pathogenesis of knee OA and accelerate joint damage.

These findings have important implications for healthy subjects and patients with knee OA. In some healthy aging subjects maintenance of quadriceps strength and proprioceptive acuity may help prevent or delay the onset of knee OA. While for patients with established knee $\mathrm{OA}$, if rehabilitation can improve quadriceps 
sensorimotor function this may increase their confidence and promote personal independence, alleviating the personal and socioeconomic burden of this disabling condition.

The authors are very grateful to the Arthritis and Rheumatism Council for their financial support of this project. We would also like to thank the staff in the Rheumatology Department of King's Healthcare, London, for their help during this trial and in particular patients who gave up their time to participate. We are particular patients who gave up their time to participate. We are
also indebted to Matt Mills and Dave McIntyre for technical help, and Dr Peter Milligan for his guidance with the statistical presentation of the results.

1 Badley E, Rasooly I, Webster G. Relative importance of musculoskeletal disorders as a cause of chronic health problems, disability, and health care utilization: Findings from the 1990 Ontario Health Survey. J Rheumatol 1994;21:505-14

2 McAlindon T E, Cooper C, Kirwan J R, Dieppe P A. Determinants of disability in osteoarthritis of the knee. Ann Rheum Dis 1993;52:258-62.

3 Gabriel S E, Crowson C S, Campion M E, O'Fallon W M Indirect and non-medical costs among people with Indirect and non-medical costs among people with rheumatoid arthritis and osteoarthritis compared

4 Fisher N M, Pendergast D R, Gresham G E, Calkins E Muscle rehabilitation: its effect on muscular and functional performance of patients with knee osteoarthritis. Arch Phys Med Rehabil 1991;72:367-74.

5 Hurley M V, Newham D J. The influence of arthrogenous muscle inhibition on quadriceps rehabilitation of patients with early, unilateral osteoarthritic knees. Br J Rheumato 1993;32:127-31.

6 Lankhorst G, Van de Stadt R, Van der Korst J. The relationships of functional capacity, pain, and isometric and isokinetic torque in osteoarthritis of the knee. Scand J Rehab Med 1985;17:167-72.

7 Fitzpatrick R, McCloskey D. Proprioceptive, visual and vestibular thresholds for the perception of sway during standing in humans. J Physiol 1994;478.1:173-86.

8 Lord S R, Lloyd D G, Li. S K. Sensori-motor function, gait patterns and falls in community-dwelling women. Age patterns and falls in

9 Baldissera F, Hultborn H, Illert M. Integration in spinal neurone systems. In: Brooks V, ed. Handbook of physiology. Bethesda, Maryland: American Physiological Society, 1981: 509-97.

10 Matthews P B C. Proprioceptors and their contribution to somatosensory mapping: complex messages require com-
plex processing. Can J Physiol Pharmacol 1988;66:430-8

11 McClosky D I. Kinaesthetic sensibility. Physiol Rev 1978;58:763-820.

12 Claessens A A, Schouten J S, van den Ouweland F A, Valkenburg H A. Do clinical findings associate with radiographic osteoarthritis of the knee? Ann Rheum Dis 1990;49:771-4.

13 Cushnaghan J, Cooper C, Dieppe P, Kirwan J, McAlindon T. Clinical assessment of osteoarthritis of the knee. Ann Rheum Dis 1990;49:768-70.

14 Scott D. Guidelines for the diagnosis, investigation and management of osteoarthritis of the hip and knee. J R Coll management of osteoarthritis of

15 Altman R, Asch E, Bloch D, Bole G, Borenstein D, Brand $\mathrm{K}$, et al. Development of criteria for the classification and reporting of osteoarthritis: classification of osteoarthritis of the knee. Arthritis Rheum 1986;29:1039-49.

16 Rutherford O M, Jones D A, Newham D J. Clinical and experimental application of the twitch superimposition technique for the study of human muscle. J Neurol Neurosurg Psychiatry 1986;49:1288-91.

17 McComas A J, Kereshi S. A method for detecting functional weakness. J Neurol Neurosurg Psychiatry 1983;46:280-2.

18 Allen G M, Gandevia S C, McKenzie D K. Reliability of measurement of muscle strength and voluntary activation using twitch interpolation. Muscle Nerve 1995;18:593600 .

19 Hurley M V. Muscle function, inhibition and rehabilitation following traumatic and degenerative joint damage. $[\mathrm{PhD}$ lowing traumatic and degenerative joint damas

20 Hurley M V, Ng T S. The reliability, reproducibility and validity of two methods of assessing proprioceptive acuity validity of two methods of assessing proprioceptive acuity

21 Mills M, McIntyre D. A new device for use in the measurement of postural sway. J Physiol 1993;473:12P.

22 Grace E M, Gerecz E M, Kassam Y B, Buchanan H B, Watson Buchanan W, Tugwell P S. 50-foot walking time: A critical assessment of an outcome measure in clinical therapeutic trails of antirheumatic drugs. Br J Rheumato 1988;27:372-4

23 Mathias S, Nayak U S L, Isaacs B. Balance in the elderly: The "get-up and go" test. Arch Phys Med Rehab 1986;67: $387-9$.

24 Lequesne M, Mery C, Samson M, Gerard P. Indexes of severity for osteoarthritis of the hip and knee: Validationvalue in comparison with other assessments. Scand J Rheumatol 1987; suppl 65:85-9.

25 Fiatarone M, Marks E, Ryan N. High intensity strength training in nonagenarians: effects on skeletal muscle. JAMA 1990;263:3029-34.

26 Grimby G, Saltin B. The ageing muscle. Clin Physiol 1983; 3:209-18.
27 Murray M P, Duthie E H, Gambert S R, Sepic S B, Mollinger L A. Age-related difference in knee muscle strength in normal women. J Gerontol 1985;40:275-80.

28 Rutherford O, Jones D. The relationship between muscle and bone loss and activity levels with age in women. Age Ageing 1992;21:286-93.

29 Young A, Stokes M, Crowe M. Size and strength of the quadriceps muscles of young and old women. Eur J Clin Invest 1984;14:282-7.

30 Hurley M V, Rees J, Newham D J. Quadriceps function, proprioceptive acuity and functional performance in healthy young, middle-aged and elderly subjects. Age Ageing (in press)

31 Vandervoot A A, McComas A J. Contractile changes in opposing muscles of the human ankle joint with ageing. J Appl Physiol 1986;48:1138-44.

32 Arvidsson I, Eriksson E, Knutsson E S A. Reduction of pain inhibition on voluntary muscle activation by epidural analgesia. Orthopedics 1986b;9:1415-9.

33 Jones D A, Jones D W, Newham D J. Chronic knee effusion and aspiration: the effect on quadriceps inhibition. $\mathrm{Br} \mathrm{J}$ Rheumatol 1987;26:370-4.

34 Spencer J D, Hayes K C, Alexander I J. Knee joint effusion and quadriceps inhibition in man. Arch Phys Med Rehabil 1984;65:171-7.

35 Shakespeare D T, Stokes M, Sherman K P, Young A. Reflex inhibition in the quadriceps after meniscectomy; lack of association with pain. Clin Physiol 1985;5:137-44.

36 Jayson M I, Dixon A S J. Intra-articular pressure in rheumatoid arthritis of the knee: I. Pressure changes during passive joint distension. Ann Rheum Dis 1970;29:261-5.

37 Schaible H-G, Neugebauer V, Cervero F, Schmidt R, F. Changes in tonic descending inhibition of spinal neurons with articular input during the development of acute arthritis in the cat. J Neurophysiol 1991;66:1021-32.

38 Appelberg B, Hulliger M, Johansson H, Sojka P. Actions on $\alpha$-motorneurones elicited by electrical stimulation of group I, II and III muscle afferent fibres in the hind limb of the cat. J Physiol 1983;335:237-92

39 Lundberg A, Malmgren K, Schomburg E D. Role of joint afferents in motor control exemplified by effects of reflex pathways from Ib afferents. J Physiol 1978;284:327-43.

40 McCrea D A. Can sense be made of spinal interneuron circuits? Behav Brain Sci 1992; 15:633-43.

41 Ellaway P H, Trott J R. Autogenic reflex action on to gamma motorneurones by stretch of triceps surae in the decerebrated cat. J Physiol 1978;276:49-66.

42 Freeman M A R, Wyke B. Articular reflexes at the ankle oint: an electromyographic study of normal and abnormal nfluences of ankle-joint mechanoreceptors upon reflex activity in the leg muscles. J Bone Joint Surg 1967b;54: 990-1001.

43 Ferrell W R, Baxendale R H, Carnachan C, Hart I K. The influence of joint afferent discharge on locomotion, proprioception and activity in conscious cats. Brain Res 1985;347:41-8.

44 Johansson H, Sjolander P, Sojka P. A sensory role for the cruciate ligaments. Clin Orthop 1991;268:161-78.

45 Barrett D S, Cobb A G, Bentley G. Joint proprioception in normal, osteoarthritic and replaced knees. J Bone Joint Surg 1991;73B:53-6.

46 Ferrell W, Crighton A, Sturrock R. Position sense at the proximal interphalangeal joint is distorted in patients with theumatoid arthritis of finger joints. Exper Physiol 1992;77:678-80.

47 Radin E L, Yang K H, Riegger C, Kish V L, O'Connor J J. Relationship between lower limb dynamics and knee joint pain. J Orthop Res 1991;9:398-405.

48 Radin E, Martin B, Burr D, Caterson B, Boyd R, Goodwin C. Effects of mechanical loading on the tissues of the rabbit knee. J Orthop Res 1984;2:221-34.

49 Jefferson R J, Radin E L, O'Connor J J. the role of the quadrcieps in controlling impulsive forces around heel strike. Proc Inst Mech Eng 1990;204:21-8.

50 O'Connor B L, Palmoski M J, Brandt K D. Neurogenic acceleration of degenerative joint lesions. J Bone Joint Surg 1985;67A:562-72

51 O'Connor B L, Visco D M, Brandt K D, Albrecht M, O'Connor A B. Sensory nerves only temporarily protect the unstable canine knee joint from osteoarthritis. Arthritis Rheum 1993;36:1154-63.

52 Wegener L, Kisner C, Nichols D. Static and dynamic balance responses in persons with bilateral knee osteoarthritis. J Orthop Sports Phys Ther 1997;25:13-8.

53 Ekdahl C, Andersson S I. Standing balance in Rheumatoid Arthritis. Scand J Rheum 1989;18:33-42.

54 Era P, Heikkinen E. Postural sway during standing and unexpected disturbance of balance in random samples of men of different ages. J Gerontol 1985;40:287-95.

55 Hughes M A, Duncan P W, Rose D K, Chandler J M, Studenski S A. The relationship of postural sway to ensorimotor function, functional performance and disability in the elderly. Arch Phys Med Rehabil 1996;77:567-72.

56 Duncan P, Chandler J, Studenski S, Hughes M, Prescott B. How do physiological components of balance affect mobility in elderly men. Arch Phys Med Rehabil 1993;74: 1343-9. 